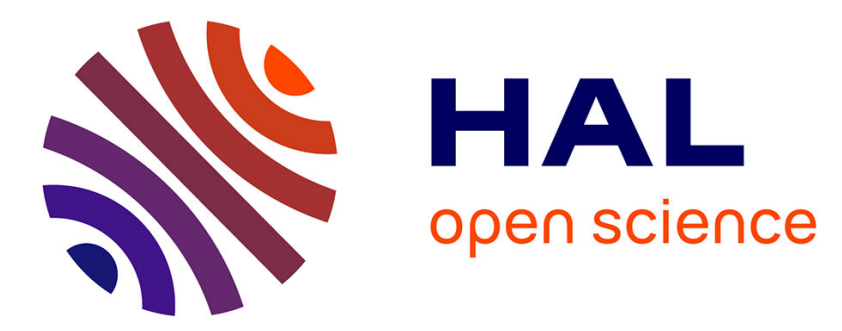

\title{
Characterisation of radial vibration force and vibration behaviour of a PWM-fed fractional-slot induction machine
}

Jean Le Besnerais, Vincent Lanfranchi, Michel Hecquet, Guy Friedrich, Pascal Brochet

\section{To cite this version:}

Jean Le Besnerais, Vincent Lanfranchi, Michel Hecquet, Guy Friedrich, Pascal Brochet. Characterisation of radial vibration force and vibration behaviour of a PWM-fed fractional-slot induction machine. IET Electric Power Applications, 2009, 3 (3), pp.197-208. 10.1049/iet-epa.2008.0099 . hal-01713732

\section{HAL Id: hal-01713732 \\ https://hal.science/hal-01713732}

Submitted on 20 Feb 2018

HAL is a multi-disciplinary open access archive for the deposit and dissemination of scientific research documents, whether they are published or not. The documents may come from teaching and research institutions in France or abroad, or from public or private research centers.
L'archive ouverte pluridisciplinaire HAL, est destinée au dépôt et à la diffusion de documents scientifiques de niveau recherche, publiés ou non, émanant des établissements d'enseignement et de recherche français ou étrangers, des laboratoires publics ou privés. 


\title{
Characterisation of radial vibration force and vibration behaviour of a PWM-fed fractional-slot induction machine
}

Jean Le Besnerais ${ }^{1 a}$, Vincent Lanfranchi ${ }^{2 a}$, Michel Hecquet ${ }^{1 b}$, Guy Friedrich ${ }^{2 b}$ and Pascal Brochet $^{1 c}$

${ }^{1 a}$ Laboratoire d'Electricité et d'Electronique de Puissance de Lille (L2EP) - Ecole Centrale de Lille, 59651 Villeneuve d'Ascq, France (jean.le_besnerais@centraliens.net)

${ }^{1 b}$ L2EP (michel.hecquet@ec-lille.fr)

${ }^{1 c}$ L2EP (pascal.brochet@ec-lille.fr)

${ }^{2 a}$ Laboratoire d'Electromécanique de Compiègne (LEC) - Université de Technologie de Compiègne, 60200 Compiègne, France (vincent.lanfranchi@utc.fr)

${ }^{2 b}$ LEC (guy.friedrich@utc.fr)

\begin{abstract}
This paper presents the full analysis of the vibration behaviour responsible for audible magnetic noise in a PWM-fed fractional-slot induction machine, including theoretical predictions, numerical simulations, and experimental validations (stator modal analysis and deflection shapes visualisation). Magnetic force waves due to slotting harmonics, pulse-width modulation (PWM) harmonics and their interactions are characterised in terms of nodes number, rotation speed, and propagation direction.

It is shown in particular that some odd spatial order vibration waves appear due to fractional slotting, and that some combinations between slotting lines and PWM lines can be very noisy due to an elliptical mode natural frequency close from the switching frequency.
\end{abstract}

\section{Keywords}

Induction machine, magnetic noise, vibrations, fractional winding, experimental modal analysis, operational deflection shapes. 


\section{Nomenclature}

$f_{c} \quad$ PWM chopping frequency

$f_{s} \quad$ Fundamental stator supply frequency

$f_{s}^{n} \quad$ Stator current $n$-th time harmonic

$f_{R} \quad$ Rotor mechanical frequency $\left(f_{R}=f_{s}(1-s) / p\right)$

$h_{s} \quad$ Integers involved in stator magnetomotive force

(mmf) Fourier series

$k_{r}, k_{s}$ Integers involved in permeance Fourier series

$p \quad$ Number of pole pairs

$q_{s} \quad$ Number of stator phases

$s \quad$ Fundamental slip

$Z_{r} \quad$ Number of rotor slots

$Z_{s} \quad$ Number of stator slots

\section{Introduction}

As acoustic comfort becomes increasingly important in electrical transport systems such as subways, tramways and trains, a full understanding of the audible magnetic noise radiation by inverterfed motors is crucial. However, this goal requires to accurately modelling both the electromagnetic excitation and the mechanical structure of the motor. Magnetic excitations come from Laplace forces, Maxwell forces and magnetostrictive forces. Laplace forces apply on stator conductors, but the magnetic flux density is too low at this place to produce significant vibrations, and conductors are wedged into the slots. Magnetostrictive vibrations can be greater than Maxwell vibrations at certain frequencies, but they are not able to excite any stator mode [1]. This article is therefore focused on Maxwell vibrations.

The attempt to characterise and reduce vibrations and acoustic noise generated by Maxwell forces in the electrical machines began with Jordan [2] and Alger [3] in the 1950's. Their work was mainly pursued by Timar [4] in the 1970's. The analytical expressions of Maxwell forces frequencies in the case of a sinusoidal supply current were found early, including the effect of 
slotting, non-sinusoidally distributed windings, saturation and eccentricities. The expression of Maxwell force waves number of nodes in function of $p, Z_{r}$ and $Z_{s}$ was derived at the same time. The characterisation of the PWM force waves was studied later in the 1980's, especially by Belmans [5-7]. However, the influence of the interaction between slotting and PWM harmonics was only pointed out in 2000's by Lo [8], Okuyama [9] and Hubert [10]. The distinction between rotating and standing force waves was first done by Zhu and Howe [11] in an analytical vibro-acoustic model. Later, Verma and Balan $[12,13]$ experimentally studied the vibratory influence of these types of exciting force waves by using a special winding, and feeding the motor with single-phase or three-phase currents.

All these interesting works present analytical calculations that do not enable a systematic association between a given magnetic force wave frequency and its corresponding number of nodes. Moreover, they generally do not make the distinction between clockwise or anti-clockwise rotating waves, and no experimentation has checked the difference between standing and rotating waves (Verma and Balan have artificially built these force waves, but they did not experimentally observe this standing or rotating property in a standard motor). Finally, the emergence of odd order vibrations waves has not been studied yet.

The goal of this article is to shed further light on these several points. Indeed, if many authors aim at reducing magnetic noise due to PWM [14-19], a clear computation of the physical properties of magnetic force waves caused by PWM has not been done yet.

Firstly, this paper derives the expressions of the spatial orders ${ }^{1}$, frequencies and propagation direction of the noisiest magnetic vibration lines due to slotting harmonics, PWM harmonics and their interaction. A different formalism is used in order to be able to quickly associate a given vibration wave frequency to its right number of nodes, and a distinction between rotating and standing waves is done. This theoretical work is based on a series of analytical models which were implemented in a fast simulation tool, Diva [20]. This software is able to compute the magnetic sound power level radiated by the motor, but only its magnetic force and vibration models are used in this paper. It also allows a virtual separation of vibration harmonics in function of their origin, and its numerical results are used in the article to check the validity of the analytical computation

\footnotetext{
${ }^{1}$ Spatial order of a force wave corresponds to its spatial frequency, and equals half its number of nodes.
} 
method. The test motor is a three-phase, squirrel cage, $700 \mathrm{~W}$ fractional-slot induction machine ( $p=2, Z_{s}=27$ and $\left.Z_{r}=21\right)$. Thanks to an improvement of the electromagnetic model presented in [10], odd slot numbers are shown to produce odd order magnetic force waves (especially 1 and 3), and the high resonance experimented in [10] due to the interaction between slotting and PWM harmonics is analytically identified.

Secondly, an experimental modal analysis is done to validate Diva natural frequencies computation. Finally, stator deflections are visualised in order to check the frequency, spatial order and propagation direction of main magnetic vibration waves due to slotting and PWM, even without resonance effect.

\section{Analytical models and theoretical predictions}

\subsection{Electromagnetic, mechanical, vibration and acoustic models}

The magnetic exciting force responsible for magnetic noise is supposed to come from the radial component of the air-gap Maxwell stress (its tangential component is neglected [4,14,21], as well as magnetostrictive effects [22]).

The electromagnetic model is based on an extended equivalent circuit for currents computation [23] and the winding functions formalism [24-26] for magnetomotive forces computation (Fig. 1), which is able to model any type of winding (shorted-pitch, fractional-slot, etc). The radial air-gap flux density $B_{g}$ is obtained as the product of permeance and magnetomotive forces, and validated by finite element method (FEM) [20].

The magnetic force per unit area $P_{M}$ applied on the inner stator surface (Fig. 2) is then approximated by $[4,27-29]$

$$
P_{M}=B_{g}^{2} /\left(2 \mu_{0}\right)
$$

In Figure 2, the Maxwell force distribution has $2 p=4$ maxima as it is a quadratic function of the air-gap flux density. Its discontinuities are due to stator and rotor slotting, and its asymmetrical shape is due to the fractional-slot winding. Note that this slotting effect is also responsible for 
torque ripple, which can be reduced by active methods [30].

The $2 \mathrm{D}$ discrete Fourier transform $P_{m \omega}$ of the magnetic radial force is then computed, and static deflections of the stator are analytically found from the expression of a cylinder deflection loaded with a sinusoidal force [31]. The natural frequencies of the stator are analytically determined using an equivalent 2D ring model, whose mass density contains the winding and teeth mass. The 3D effects are accounted for by using Cremer coefficients [23]. The damping factor is approximated using the empirical law proposed by Yang [32]. From damping factors and natural frequencies are finally determined the dynamic deflections of the stator, and the corresponding magnitudes of vibration waves. This vibration model can be easily extended to the sound power level determination using an analytical model of radiation efficiency [33]. In that case, the A-weighted curve is used in order to account for the human's ear sensitivity in function of frequency. However, the acoustic part of the simulation tool Diva is not used in this article.

More details about Diva model, which has been validated at several levels with tests and FEM, can be found in $[20,34]$.

\subsection{Analytical predictions}

In order to find the expression of Maxwell forces spatial orders and frequencies, permeance and magnetomotive functions are developed in 2D Fourier series. They are therefore represented by a series of rotating wave $\left(m_{i}, f_{i}\right), m_{i}$ being the spatial order of the wave, and $f_{i}$ being its electrical frequency (the wave mechanical rotation speed is then $f_{i} / m_{i}$ ). All these waves are rotating in the air-gap, apart when $m_{i}=0$, or when two waves of same magnitude and same order rotate in opposite directions (case of pulsating waves, also called standing waves as their nodes speed is null, cf. Fig. 3).

The Maxwell force waves are obtained by multiplying the flux density waves one with another ; flux density waves are given by permeance and mmf waves multiplication. When two waves $\left(f_{1}, m_{1}\right)$ and $\left(f_{2}, m_{2}\right)$ are multiplied, they generate two additional waves $\left(f_{1}+f_{2}, m_{1}+m_{2}\right)$ and $\left(f_{1}-f_{2}, m_{1}-m_{2}\right)$ which can be represented by $\left(f_{1}+\epsilon f_{2}, m_{1}+\epsilon m_{2}\right)$ where $\epsilon= \pm 1$. The use of $\epsilon$ instead of \pm 1 in the force waves expression makes it easier to associate a given frequency to its 
spatial order formula, and reciprocally.

Permeance and stator mmf waves are characterised in Table $1[34,35]$, where $P_{s}$ (resp. $P_{r}$ ) waves represent stator (resp. rotor) slotting harmonics contribution, and $P_{s r}$ represent their interaction. Saturation and eccentricities effects are here neglected.

Table 1: Permeance and stator mmf waves characterisation

\begin{tabular}{|c|c|c|c|}
\hline Name/Amplitude & Spatial orders & Frequencies & Comments \\
\hline \hline$P_{0}$ & 0 & 0 & \\
$P_{s}$ & $k_{s} Z_{s}$ & 0 & $k_{r}, k_{s} \geq 1$ \\
$P_{r}$ & $k_{r} Z_{r}$ & $k_{r} Z_{r} f_{R}$ & \\
$P_{s r}$ & $k_{s} Z_{s} \pm k_{r} Z_{r}$ & $\pm k_{r} Z_{r} f_{R}$ & \\
$F_{s}$ & $p \pm q_{s} h_{s}$ & $\pm f_{s}^{n}$ & $h_{s} \geq 0$ \\
\hline
\end{tabular}

\subsubsection{Fundamental lines}

If we consider an ideal machine with an ideal frequency inverter, a sinusoidal mmf and a smooth air-gap, the only Maxwell force harmonics are a DC component (order 0, frequency $0 \mathrm{~Hz}$ ) and an AC component of same magnitude (order $2 p$, frequency $2 f_{s}$ ). These fundamental force lines orders generate low static and dynamic deflections, and have also very low frequencies: they are either inaudible, or covered by mechanical noise.

\subsubsection{Slotting magnetic lines}

Taking the fundamental stator mmf wave $F_{s}=\left(p, f_{s}\right)$, and combining the flux density waves $P_{r} F_{s}=\left(k_{r} Z_{r}+\epsilon_{r} p, k_{r} Z_{r} f_{R}+\epsilon_{r} f_{s}\right)$ with $P_{s} F_{s}=\left(k_{s} Z_{s}+\epsilon_{s} p, \epsilon_{s} f_{s}\right)$, the following Maxwell force waves appear:

$$
P_{r} F_{s} P_{s} F_{s}=
$$$$
\left(k_{r} Z_{r}+\epsilon k_{s} Z_{s}+\left(\epsilon_{r}+\epsilon \epsilon_{s}\right) p, k_{r} Z_{r} f_{R}+\left(\epsilon_{r}+\epsilon \epsilon_{s}\right) f_{s}\right)
$$

These force waves can only be noisy if they have low spatial orders ( 0 to 4$)$, i.e. for $\epsilon=-1$ as $k_{r}$ and $k_{s}$ are positive integers. Furthermore, their magnitude decrease with $k_{r}$ and $k_{s}$ with the following law $[35]$ 


$$
P_{s} \propto 1 / k_{s} \quad P_{r} \propto 1 / k_{r}
$$

These force waves can be called pure slotting waves, as they are given by the combination between slotting harmonics and the fundamental stator mmf wave: if they are noisy in sinusoidal case, they will remain noisy in PWM case. In addition, the parity of their spatial order $\bar{m}^{2}$ in our test motor $\left(Z_{s}=27, Z_{r}=21\right)$ is given by:

$$
\bar{m}=\overline{k_{r} Z_{r}}+\epsilon \overline{k_{s} Z_{s}}=\overline{k_{r}}+\epsilon \overline{k_{s}}
$$

As $k_{s}$ and $k_{r}$ can be even or odd, some odd order vibration can occur on our test motor. In fact, a necessary and sufficient condition to have a slotting vibration of odd order is to have an odd number of stator slots, and/or an odd number of rotor slots, independently of the number of pole pairs. Induction machines usually have an integral winding, which imposes an even $Z_{s}$, while $Z_{r}$ is also chosen even in order to avoid magnetic pull [36]: as a consequence, only even order magnetic vibrations usually occur.

Table 2 shows the expressions of the main slotting force waves (order 0 to 4 ) occurring on our test motor (in decreasing magnitude order).

\subsubsection{PWM magnetic lines}

Pure PWM force waves are given by the combination between fundamental flux density $\left(p, f_{s}\right)$ and its time harmonics $\left(p, f_{s}^{n}\right)$. The resulting forces are thus given by $\left(0, f_{s}^{n}-f_{s}\right)$ and $\left(2 p, f_{s}^{n}+f_{s}\right)$.

Our test motor is supplied with an asynchronous PWM generated by a sawtooth-shaped carrier which produces a first group of current harmonics at frequencies $f_{s}^{n}= \pm f_{c}+f_{s}$ and $\pm f_{c}-2 f_{s}$. The resulting PWM force lines are displayed in Table 3.

\subsubsection{PWM and slotting lines combinations}

Combining flux density waves $P_{s} F_{s}$ coming from stator slotting and stator fundamental mmf, with flux density waves $P_{r} F_{n}^{s}$ coming from rotor slotting and stator mmf PWM harmonics give rise to

\footnotetext{
${ }^{2}$ By definition, $\bar{m}$ equals 0 if $m$ is even, and 1 if $m$ is odd.
} 
Table 2: Characterisation of test motor main slotting vibration lines.

\begin{tabular}{|c|c|c|c|c|c|c|}
\hline nb. & $k_{s}$ & $k_{r}$ & $\epsilon_{s}$ & $\epsilon_{r}$ & Order $m$ & Frequency $f(\mathrm{~Hz})$ \\
\hline \hline 1 & 1 & 1 & -1 & 1 & -2 & $f_{s}\left(Z_{r}(1-s) / p+2\right)$ \\
3 & 3 & 4 & 1 & -1 & -1 & $f_{s}\left(4 Z_{r}(1-s) / p-2\right)$ \\
& 3 & 4 & \pm 1 & \pm 1 & 3 & $f_{s}\left(4 Z_{r}(1-s) / p\right)$ \\
4 & 4 & 5 & \pm 1 & \pm 1 & -3 & $f_{s}\left(5 Z_{r}(1-s) / p\right)$ \\
5 & 4 & 5 & -1 & 1 & 1 & $f_{s}\left(5 Z_{r}(1-s) / p+2\right)$ \\
6 & 6 & 8 & 1 & -1 & 2 & $f_{s}\left(8 Z_{r}(1-s) / p-2\right)$ \\
& 7 & 9 & 1 & -1 & -4 & $f_{s}\left(9 Z_{r}(1-s) / p-2\right)$ \\
7 & 7 & 9 & \pm 1 & \pm 1 & 0 & $f_{s}\left(9 Z_{r}(1-s) / p\right)$ \\
& 7 & 9 & -1 & 1 & 4 & $f_{s}\left(9 Z_{r}(1-s) / p+2\right)$ \\
8 & 8 & 10 & -1 & 1 & -2 & $f_{s}\left(10 Z_{r}(1-s) / p+2\right)$ \\
9 & 10 & 13 & 1 & -1 & -1 & $f_{s}\left(13 Z_{r}(1-s) / p-2\right)$ \\
10 & 10 & 13 & \pm 1 & \pm 1 & 3 & $f_{s}\left(13 Z_{r}(1-s) / p\right)$ \\
& 11 & 14 & \pm 1 & \pm 1 & -3 & $f_{s}\left(14 Z_{r}(1-s) / p\right)$ \\
& 11 & 14 & -1 & 1 & 1 & $f_{s}\left(14 Z_{r}(1-s) / p+2\right)$ \\
& 13 & 17 & 1 & -1 & 2 & $f_{s}\left(17 Z_{r}(1-s) / p-2\right)$ \\
& 14 & 18 & 1 & -1 & -4 & $f_{s}\left(18 Z_{r}(1-s) / p-2\right)$ \\
11 & 14 & 18 & \pm 1 & \pm 1 & 0 & $f_{s}\left(18 Z_{r}(1-s) / p\right)$ \\
& 14 & 18 & -1 & 1 & 4 & $f_{s}\left(18 Z_{r}(1-s) / p+2\right)$ \\
\hline
\end{tabular}

Table 3: Characterisation of test motor main PWM vibration lines.

\begin{tabular}{|c|c|}
\hline Spatial order $m$ & Frequency $f$ \\
\hline \hline 0 & $f_{c}-3 f_{s}$ \\
$-2 p=-4$ & $f_{c}-2 f_{s}$ \\
$2 p=4$ & $f_{c}-f_{s}$ \\
0 & $f_{c}$ \\
$-2 p=-4$ & $f_{c}+f_{s}$ \\
$2 p=4$ & $f_{c}+2 f_{s}$ \\
0 & $f_{c}+3 f_{s}$ \\
\hline
\end{tabular}

the force waves

$$
P_{r} F_{s} P_{s} F_{s}^{n}=
$$$$
\left(k_{r} Z_{r}+\epsilon k_{s} Z_{s}+\left(\epsilon_{r}+\epsilon \epsilon_{s}\right) p, k_{r} Z_{r} f_{R}+\epsilon \epsilon_{s} f_{s}^{n}+\epsilon_{r} f_{s}\right)
$$

As in pure slotting forces case, these waves can only have low spatial orders if $\epsilon=-1$. On our test motor, for $k_{r}=k_{s}=1$ and $\epsilon_{r}=-\epsilon_{s}=1$, the main force waves due to PWM and slotting interaction are therefore given by $\left(-2, f_{s}\left(Z_{r}(1-s) / p+2\right) \pm f_{c}\right)$ and $\left(-2, f_{s}\left(Z_{r}(1-s) / p-1\right) \pm f_{c}\right)$. As 
our motor test elliptical mode is near $2400 \mathrm{~Hz}$ (see section 4.2), it can cause a resonance according to the applied switching frequency $f_{c}$ value [10].

\section{Simulation results}

In this part, the simulation tool Diva is used in order to uncouple the sources of space and time harmonics in the exciting magnetic forces, and check the analytical results of previous section. Simulations can be carried on a virtual motor with a smooth or slotted air-gap, sinusoidal or stepped magnetomotive forces, sinusoidal or PWM currents in order to distinguish in the exciting forces spectrum space and time harmonics coming from several origins. For each case, only the greatest force lines expressions are detailed for readability purpose.

Note that these simulations give an important information of magnetic force lines magnitude: as the analytical method of previous section do not consider phase angles, some destructive interferences can occur and cancel a vibration line that was theoretically dangerous (e.g. in section $3.3)$.

\subsection{Fundamental lines}

A first simulation is run with in the ideal case (no inverter time harmonics, no winding harmonics, no slotting harmonics). The resulting force spectrum is presented in Fig. 4, and consists of two lines as predicted in section 2.2.1.

\subsection{Slotting lines}

A second simulation is run on a sinusoidally-fed slotted machine (no PWM time harmonics, and no stator mmf space harmonics) in order to check slotting lines frequencies, orders and propagation direction (Fig. 5). Simulation results give the same line as computed in table 3. 


\subsection{PWM lines}

A third simulation is run in PWM no load case. As in previous simulation, stator mmf is forced to be sinusoidal, but the permeance function is also forced to be uniform in order to cancel slotting harmonics. The main force lines agree with analytical predictions (Fig. 6). The force line of order 0 and frequency $f_{c}$ has a low magnitude compared to other PWM force lines because it results from the destructive interference between the force lines $\left(0, f_{c}\right)$ and $\left(0,-f_{c}\right)$.

Pure PWM lines magnitude are thus twenty times greater than slotting lines. However, independently of resonance effects, stator displacements highly depend on the spatial orders of the exciting force waves [37]: order 2 displacements are for instance twenty times higher than order 4 displacements, so that PWM vibrations can be as noisy as slotting vibrations in compliance with tests.

\subsection{PWM and slotting lines combinations}

A last simulation is run in PWM no load case with a non-uniform air-gap and a sinusoidal mmf. In Fig. 7, the force lines of spatial orders $m= \pm 2$ in PWM case are overlaid with the same force lines in sinusoidal case: the two graphs only share a common peak at $625 \mathrm{~Hz}$, which is a pure slotting line that has already been identified in section 3.2 (line nb. 1). The other peaks of the simulated spectrum were effectively computed in section 2.2.4.

\section{Experimental results}

\subsection{Experimental set-up}

The test motor is a low voltage, three-phase $700 \mathrm{~W}$ squirrel-cage induction machine $(p=2$, $\left.Z_{s}=27, Z_{r}=21\right)$. Tests are realised with $10 \mathrm{~V}$ phase voltage and $6 \mathrm{~A}$ phase current at no load condition. Its section, as well its flux density lines distribution and its fractional-slot winding scheme are represented in Fig. 8. The motor is fed by a DSP-controlled power converter, and radial vibrations are recorded by the aid of four accelerometers (Fig. 9), besides a reference accelerometer. These three accelerometers are sequentially displaced on the mesh defined for 
the operational modal analysis (section 4.2) or operational deflection shape ((section 4.3). Data acquisition and post-processing are done in Pulse Labshop software.

\subsection{Operational modal analysis (OMA)}

An operational modal analysis (OMA) was done in order to check the natural frequencies of the motor. Contrary to the impact hammer or shaker method, the experimental modal analysis consists in using the intrinsic forces of the structure to identify its modal parameters [38]: thus, the exciting force spectrum (Maxwell forces in our case) must be as wide as possible in order to excite the system on a wide frequency range.

The accelerometers were moved on a 3 per 8 points mesh around the stator frame, and measurements were made while running the motor from 0 to $80 \mathrm{~Hz}$ with PWM at $f_{c}=1600 \mathrm{~Hz}$. The final averaged spectral density is shown in Fig. 10, and the shapes of the first five circumferential modes are displayed in Fig. 11. Table 4 favourably compares previous studies on natural frequencies calculation [23] with the analytical model predictions [34] and OMA results.

Table 4: Stator natural frequencies computation (Hz) using different methods. OR: Out of Range, ND: Non Definite.

\begin{tabular}{|c|c|c|c||c|c|}
\hline$m$ & 2-D FEM & Shock Method & Sinus Method & DIVA & OMA \\
\hline 0 & 14656 & OR & OR & 14859 & 14400 \\
1 & ND & 1200 & 1273 & 1234 & 1148 \\
2 & 2364 & 2400 & 2423 & 2485 & 2245 \\
3 & 6473 & 6100 & 6210 & 6415 & 6370 \\
4 & 11898 & 11700 & OR & 12065 & 11790 \\
\hline
\end{tabular}

\subsection{Operational deflection shapes (ODS)}

In order to validate the spatial order, the frequency and the propagation direction of pure slotting lines, an ODS analysis was run in sinusoidal case $\left(f_{s}=30 \mathrm{~Hz}\right)$ on a 16 points mesh around the stator frame median circumference. The accelerometers accuracy and the software features make it possible to visualise stator structure movements at each frequency, even when it is subjected to an exciting force far from any resonance. 
The resulting frequency response function $(\mathrm{FRF})$ is shown in Fig. 12. This FRF is different from the synthesised function obtained with the OMA (Fig. 10), as it was generated by the interaction between the exciting magnetic forces spectrum and the stator natural frequencies spectrum: when an exciting force frequency is far all the natural frequencies of the structure, the deflection shape which is visualised is a direct image of the exciting force (forced response); on the contrary, when an exciting frequency is close to a natural frequency, the visualised shape can be dominated by a modal response. This is the example of the vibration line of order 3 , and frequency $f_{s}\left(4 Z_{r}(1-s) / p\right)=1260$ $\mathrm{Hz}$ at $f_{s}=30 \mathrm{~Hz}$, whose propagation direction could not be clearly observed because the deflection shape was dominated by the bending mode response.

Most of the vibrations listed in Table 2 have been visualised, and the rotation direction of vibration waves agree with analytical results (see Fig. 13). For instance, the main slotting vibration (line nb. 1) given by $k_{r}=1$ and $k_{s}=1$ has a spatial order of $k_{r} Z_{r}-k_{s} Z_{s}+2 p=-2$ and a frequency $f_{s}\left(Z_{r} / p+2\right)$ : the stator deflection shape at that frequency is elliptical and rotates in counter-clockwise direction.

Another ODS has been done in PWM case in order to visualise pure PWM vibrations. Fig. 14 shows that their shape and propagation direction also agree with analytical predictions and simulations.

\section{Conclusion}

The most dangerous magnetic vibration waves coming from slotting, PWM supply and their interactions, have been analytically characterised to clearly associate rotation speeds, numbers of nodes and propagation directions. The emergence of odd order vibrations waves with fractional slotting has been taken into account too. Some simulations, based on analytical models, have been run in order to check these predictions. They also have been validated using some advanced vibro-acoustic tools, namely the experimental modal analysis and the deflection shapes visualisation.

Future work will carry exhaustive variable-speed simulations with the fast simulation tool DivA in order to find the quietest combinations of slot numbers on small power induction machines, as it is was done for switched reluctance machines [39] or permanent magnet brushless machines [40]. 


\section{Acknowledgements}

This work was supported in part by the French Agence De l'Environnement et de la Maîtrise de l'Energie (ADEME), and ALSTOM Transport.

\section{References}

[1] X. Mininger, N. Galopin, F. Bouillault, and M. Gabsi, "Analysis of electromagnetic strains on a structure such as switched reluctance machine," European Physical Journal - Applied Physics, vol. 39, 2007.

[2] H. Jordan, Electric motor silencer - formation and elimination of the noises in the electric motors. W. Giradet-Essen editor, 1950.

[3] P. Alger, The Nature of Polyphase Induction Machines. John Wiley \& Sons, Inc., 1951.

[4] P. Timar, Noise and vibration of electrical machines. Elsever, 1989.

[5] R. Belmans, L. D'hondt, A. Vandenput, and W. Geysen, "Analysis of the audible noise of three-phase squirrel-cage induction motors supplied by inverters," IEEE Trans. on Ind. Appl., vol. 23, Sept/Oct 1987.

[6] R. Belmans, Verdyk, Geysen, and Findlay, "Electro-mechanical analysis of the audible noise of an inverter-fed squirrel cage induction motor," IEEE Trans. Ind. Appl., vol. 27, no. 3, May/June 1991.

[7] R. Belmans and K. Hameyer, "Impact of inverter supply and numerical calculation techniques in audible noise problems," International Seminar on Vibrations and Acoustic Noise of Electric Machinery, 1998.

[8] W. Lo, C. Chan, Z. Zhu, L. Xu, D. Howe, and K. Chau, "Acoustic noise radiated by PWMcontrolled induction machine drives," IEEE Trans. on Industrial Electronics, vol. 47, no. 4, Aug. 2000. 
[9] Y. Okuyama and S. Moriyasu, "Electromagnetic noise of induction motors driven by PWM inverters," Electrical Engineering in Japan, vol. 133, no. 3, 2000.

[10] A. Hubert and G. Friedrich, "Influence of power converter on induction motor acoustic noise: interaction between control strategy and mechanical structure," IEE Proc. on Electr. Power Appl., vol. 149, Mar. 2002.

[11] Z. Zhu and D. Howe, "Improved methods for prediction of electromagnetic noise radiated by electrical machines," IEE Proc. on Electr. Power Appl., vol. 141, no. 2, pp. 109-120, 1994.

[12] S. Verma and A. Balan, "Experimental investigations on the stators of electrical machines in relation to vibration and noise problems," IEE Proc. on Electr. Power Appl., vol. 145, no. 5, 1998.

[13] — - "Electromagnetic surface excitation system for the study of vibration behaviour of stator of electrical machines," vol. 1, 1996, pp. 332-337.

[14] C. Wang, J. Lai, and A. Astfalck, "Sound power radiated from an inverter driven induction motor II : numerical analysis," IEE Proc. on Electr. Power Appl., vol. 151, no. 3, May 2004.

[15] — , "Sound power radiated from an inverter driven induction motor : experimental investigation," IEE Proc. on Electr. Power Appl., vol. 149, no. 1, Jan. 2002.

[16] C. Wang and J. Lai, "Sound power radiated from an inverter driven induction motor. part 3: statistical energy analysis," IEE Proc. on Electr. Power Appl., vol. 152, no. 3, May 2005.

[17] S. Na, Y. Jung, Y. Lim, and S. Yang, "Reduction of audible switching noise in induction motor drives using random position space vector PWM," IEE Proceedings of Electric Power Applications, vol. 149, May 2002.

[18] L. Liaw, "Random slope PWM inverter using existing system background noise: analysis, design and implementation," IEE Proc. on Electr. Power Appl., vol. 147, Jan. 2000. 
[19] S. Bologniani, A. D. Bella, and M. Zigliotto, "Random modulation and acoustic noise reduction in IM drives: a case study," IEE Proceedings of the Ninth International Conference on the Electrical Machines and Drives, 1999.

[20] J. L. Besnerais, A. Fasquelle, M. Hecquet, V. Lanfranchi, P. Brochet, and A. Randria, "A fast noise-predictive multiphysical model of the PWM-controlled induction machine," in Proc. of the International Conference on Electrical Machines (ICEM'06), Chania, Greece, July 2006.

[21] J. Gieras, C. Wang, and J. Lai, Noise of polyphase electric motors. CRC Press, Dec. 2005.

[22] L. Laftman, "Magnetostriction and its contribution to noise in a PWM inverter fed induction machine," Journal of Physics, vol. 4, no. 8, 1998.

[23] A. Hubert, "Contribution l'étude des bruits acoustiques générés lors de l'association machines électriques - convertisseurs statiques de puissances - application à la machine asynchrone," Ph.D. dissertation, Université des Technologies de Compiègne, France, Dec. 2000.

[24] A. Ghoggal, M. Sahraoui, A. Aboubou, S. Zouzou, and H. Razik, "An improved model of the induction machine dedicated to faults detection - extension of the modified winding function approach," in Proc. of the International Conference on Industrial Technology, Dec. 2005, pp. 191-196.

[25] G. Bossio, C. D. Angelo, J. Solsona, G. Garcia, and M. Valla, "A 2-D model of the induction machine: an extension of the modified winding function approach," IEEE Trans. on Energy Conversion, vol. 19, no. 1, Mar. 2004.

[26] M. Joksimovic, M. Djurovic, and J. Penman, "Cage rotor MMF : winding function approach," IEEE Power Engineering Review, vol. 21, no. 4, Apr. 2001.

[27] K. Maliti, "Modelling and analysis of magnetic noise in squirrel-cage induction motors," Ph.D. dissertation, Stockholm, 2000.

[28] A. Astfalck, "Analysis of electromagnetic force and noise in inverter driven induction motors," Ph.D. dissertation, Aug. 2002. 
[29] C. Wang, "Vibro-acoustic analysis of inverter driven induction motors," Ph.D. dissertation, The University of New South Wales, Australia, May 1998.

[30] A. Ndiaye, "Compensation active des ondulations de couple dun. moteur synchrone aimants permanents," Ph.D. dissertation, Université de Franche-Comté, Belfort, France, 2002.

[31] P. Alger, Induction machines : their behaviour and uses. Gordon and Breach Science Publishers, 1970.

[32] S. J. Yang, Low noise electrical motors. Oxford: Clarendon Press, 1981.

[33] P. Timar and J. Lai, "Acoustic noise of electromagnetic origin in an ideal frequency-converterdriven induction motor," IEE Proc. on Electr. Power Appl., vol. 141, no. 6, Nov. 1994.

[34] J. L. Besnerais, V. Lanfranchi, M. Hecquet, P. Brochet, and G. Friedrich, "Acoustic noise of electromagnetic origin in a fractional-slot induction machine," COMPEL, vol. 27, no. 5, Feb. 2008.

[35] J. Brudny, "Modélisation de la denture des machines asynchrones : phénomènes de résonances," Journal of Physics III, vol. 37, no. 7, 1997.

[36] A. Arkkio, "Unbalanced magnetic pull in cage induction motors with asymmetry in rotor structure," IEEE Proceedings of EMD, 1997.

[37] V. Lanfranchi, A. Ait-Hammouda, M. Hecquet, G. Friedrich, and A. Randria, "Vibratory and acoustic behavior of induction traction motors, vibration reduction with design machine," in Proceedings of the 2006 IAS conference, 2006.

[38] G. James, T. Carne, and J. Lauffer, "The natural excitation technique (NExT) for modal parameter extraction from operating wind turbines," Tech. Rep., Feb. 1993.

[39] M. Anwar and I. Hussain, "Radial force calculation and acoustic noise prediction in switched reluctance machines," IEEE Transaction on Industry Applications, vol. 36, no. 6, 2000.

[40] Y. Chen, Z. Zhu, and D. Howe, "Vibration of pm brushless machines having a fractional number of slots per pole," IEEE Trans. on Magnetics, vol. 42, no. 10, Oct. 2006. 


\section{$7 \quad$ Figures}

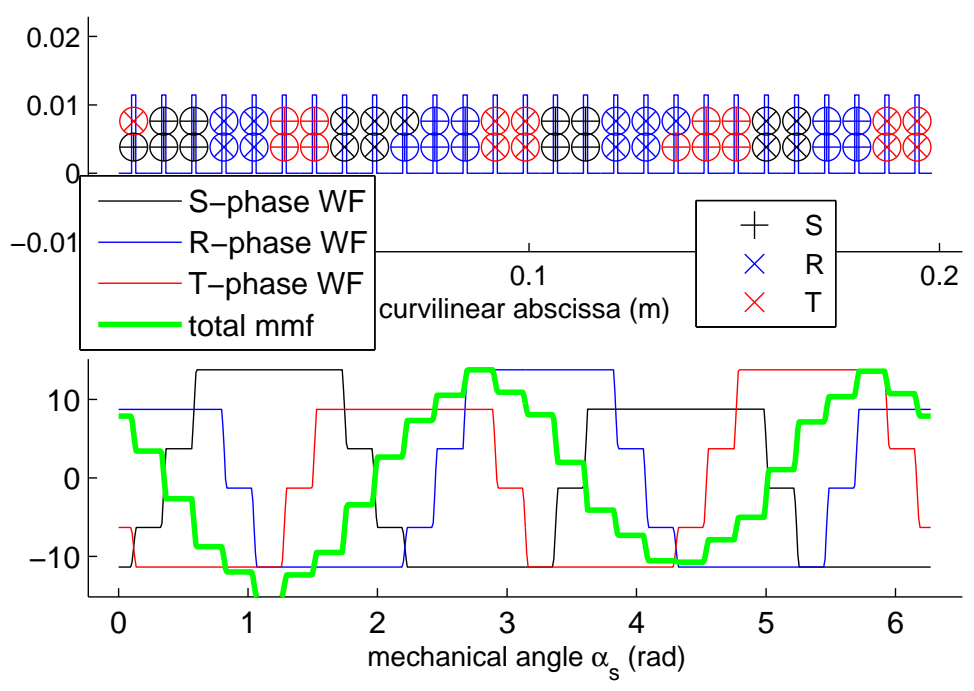

Figure 1: Winding scheme, winding functions and stator mmf of test motor.

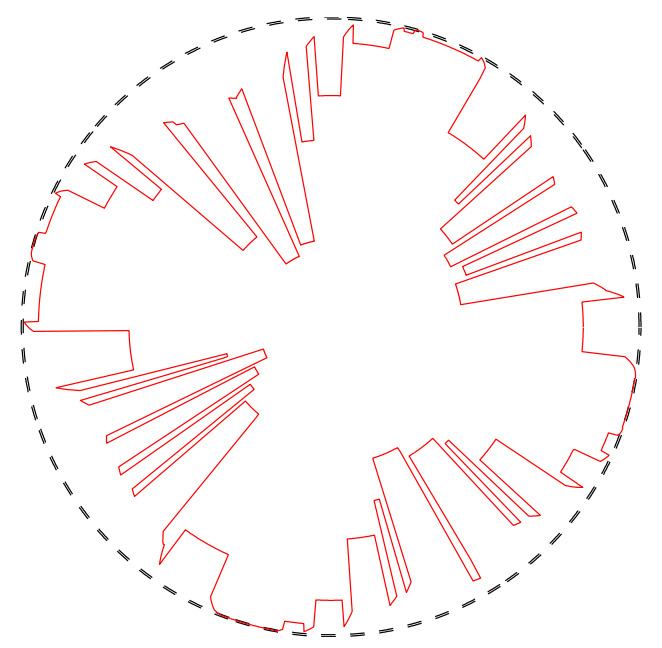

Figure 2: Maxwell radial force distribution at a given time, which tends to pull stator teeth towards the rotor. 


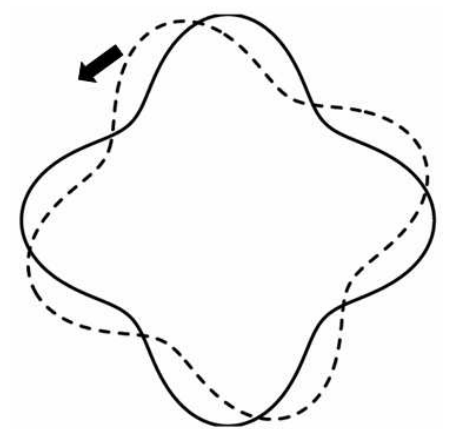

Order 4, rotating

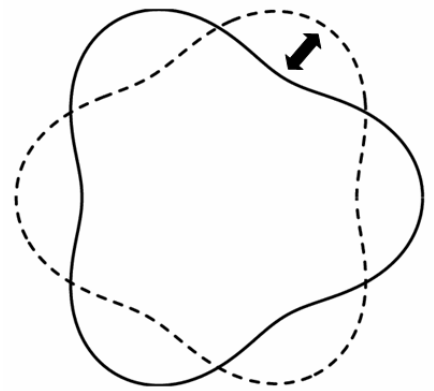

Order 3, standing

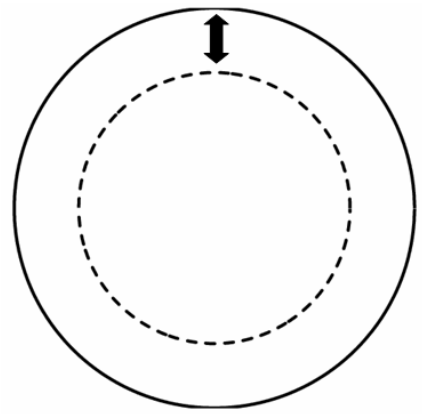

Order 0 , standing

Figure 3: Illustration of different force waves types. The nodes of rotating waves travel along the air-gap, whereas standing waves ones stay at the same place.

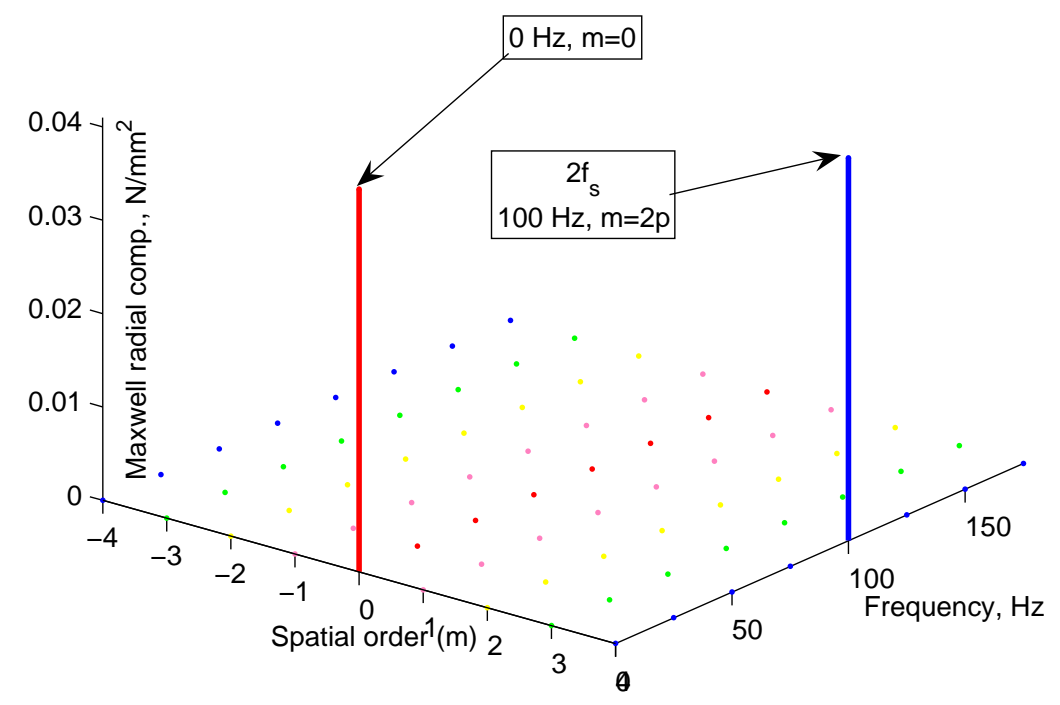

Figure 4: Fourier transform of simulated radial Maxwell force (no load sinusoidal case, sinusoidal mmf and smooth air-gap, $\left.f_{s}=50 \mathrm{~Hz}, s \approx 0\right)$ in $[0 \mathrm{~Hz}, 200 \mathrm{~Hz}]$ range. 


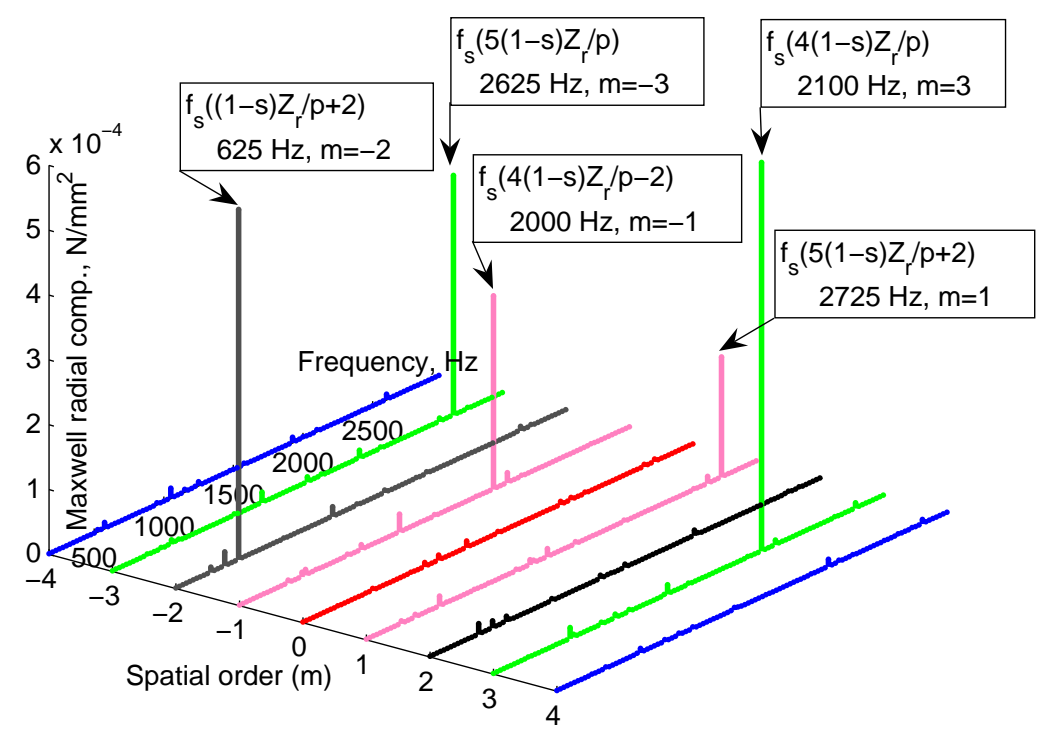

Figure 5: 2D Fourier transform of simulated radial Maxwell force (no load sinusoidal case, sinusoidal mmf, $\left.f_{s}=50 \mathrm{~Hz}, s \approx 0\right)$ in $[500 \mathrm{~Hz}, 3000 \mathrm{~Hz}]$ range.

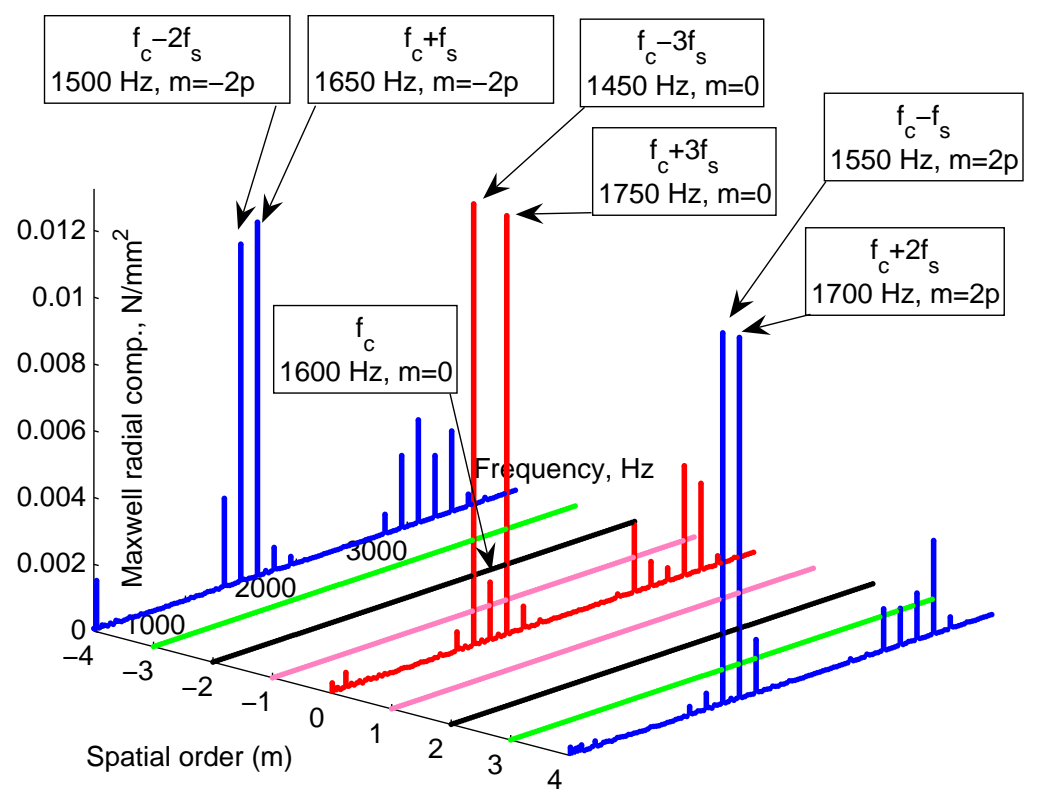

Figure 6: 2D Fourier transform of simulated radial Maxwell force (no load asynchronous PWM case, sinusoidal mmf and smooth air-gap, $\left.f_{s}=50 \mathrm{~Hz}, f_{c}=1600 \mathrm{~Hz}, s \approx 0\right)$ in $[600 \mathrm{~Hz}, 4000 \mathrm{~Hz}]$ range. 


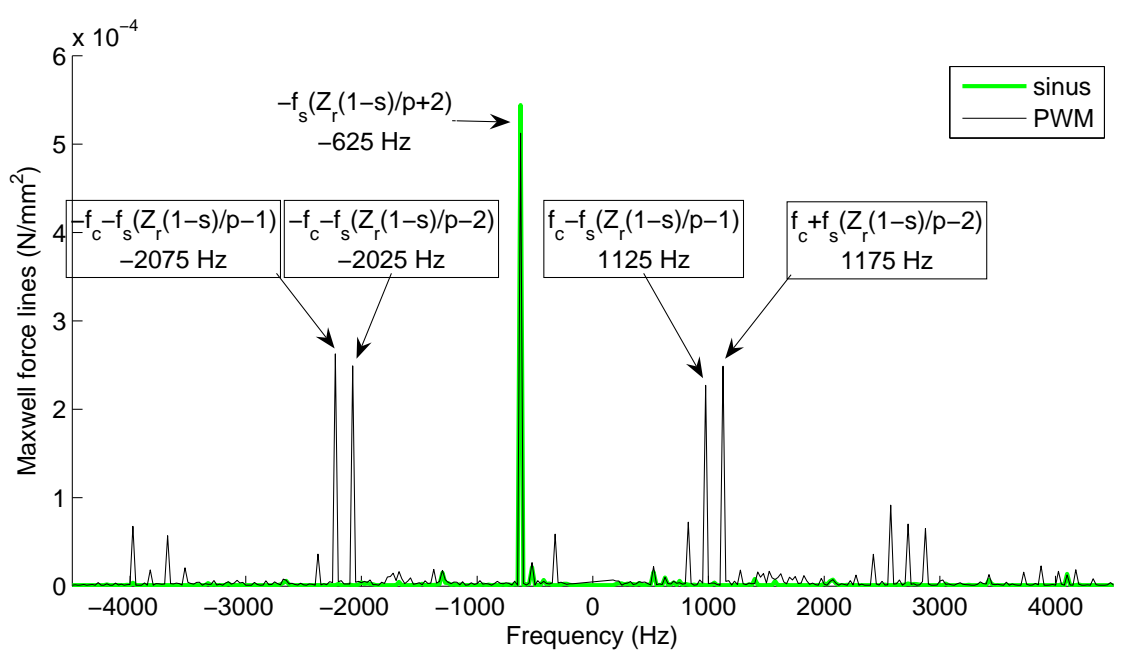

Figure 7: Simulated Maxwell forces spectra of order 2 in asynchronous PWM and sinusoidal cases $\left(f_{s}=50 \mathrm{~Hz}, f_{c}=1600 \mathrm{~Hz}, s \approx 0\right)$.

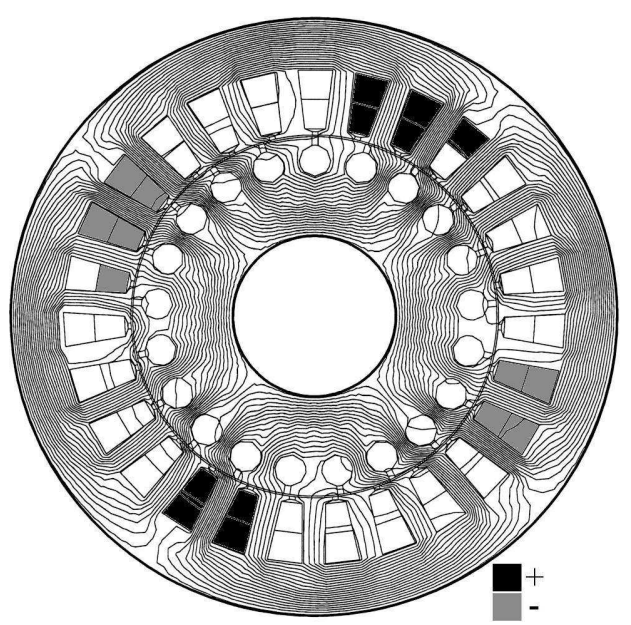

Figure 8: Test motor section, fractional-slot winding scheme and flux density lines distribution.

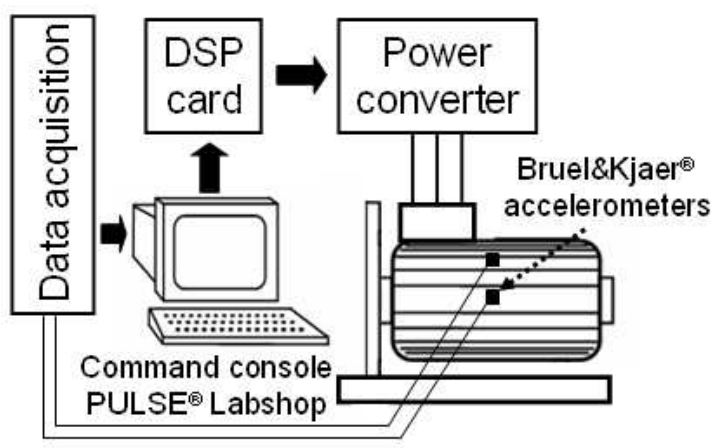

Figure 9: Experimental set-up scheme. 


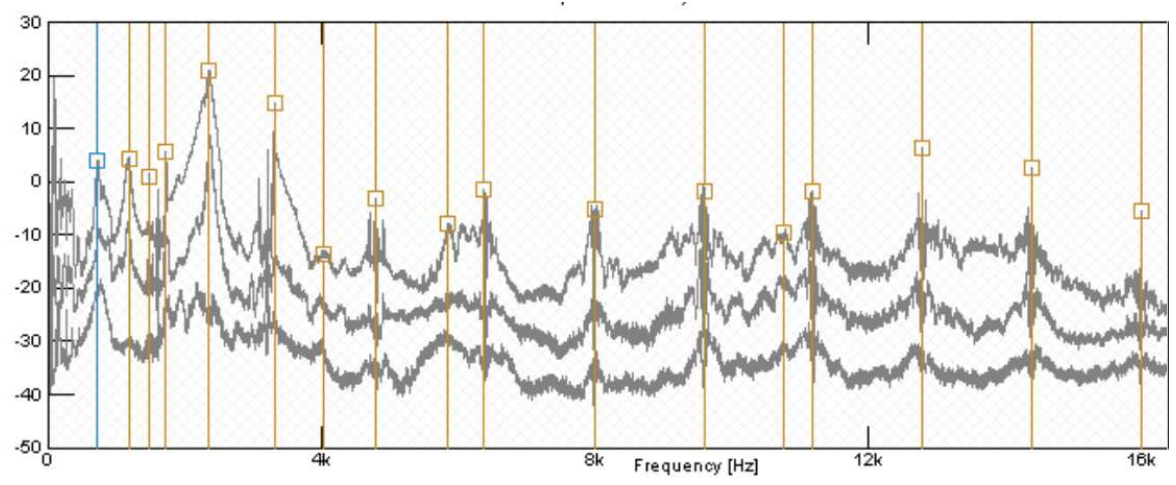

Figure 10: OMA synthesised frequency response function (PWM case, $f_{c}=1600 \mathrm{~Hz}$ ) in $[0 \mathrm{~Hz}$, $16200 \mathrm{~Hz}$ ] range. The peaks indicate the natural frequencies of stator modes (for instance, the peak around $2300 \mathrm{~Hz}$ corresponds to the stator elliptical mode).

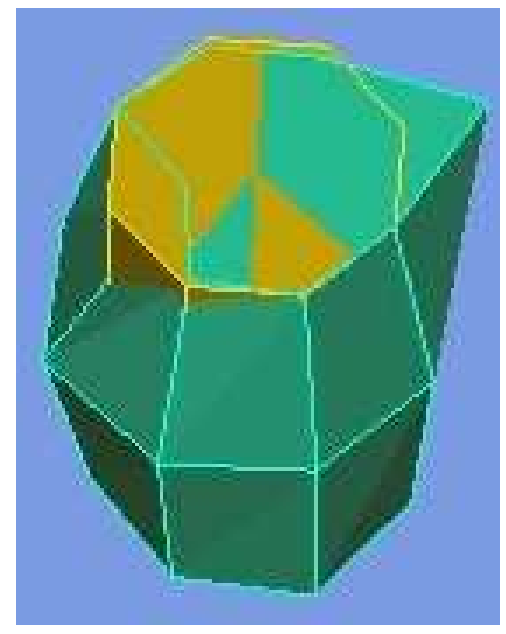

Mode 0, $14400 \mathrm{~Hz}$

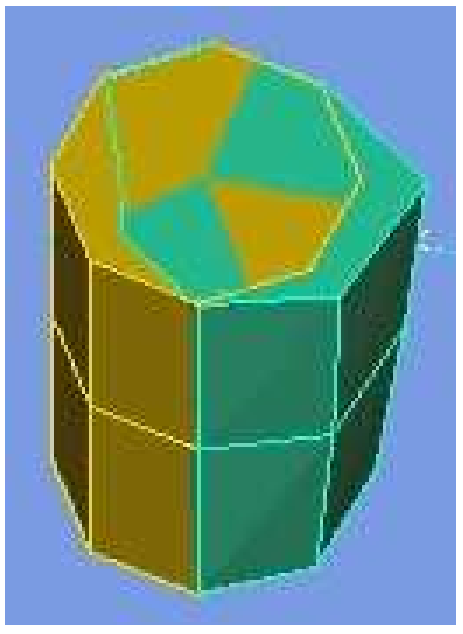

Mode 1, $1148 \mathrm{~Hz}$

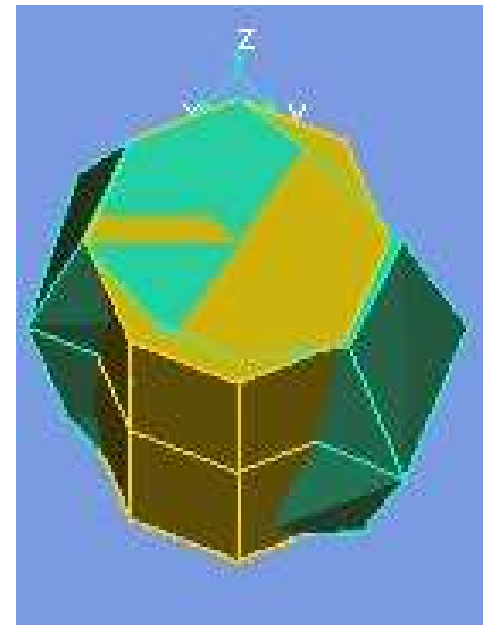

Mode 2, $2245 \mathrm{~Hz}$

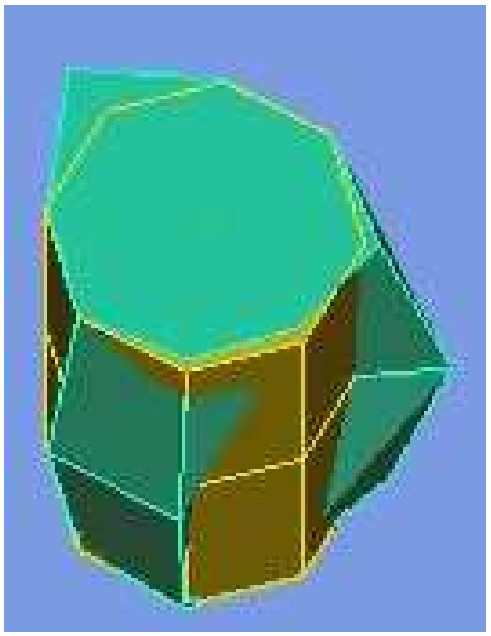

Mode 3, $6370 \mathrm{~Hz}$

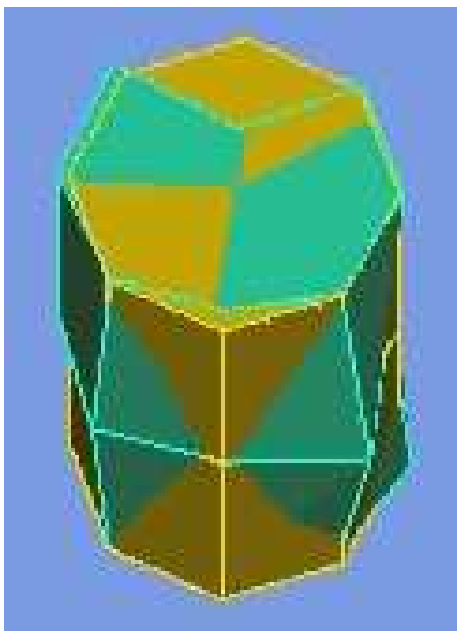

Mode 4, $11790 \mathrm{~Hz}$

Figure 11: Deflection shapes of the first five stator circumferential modes. 


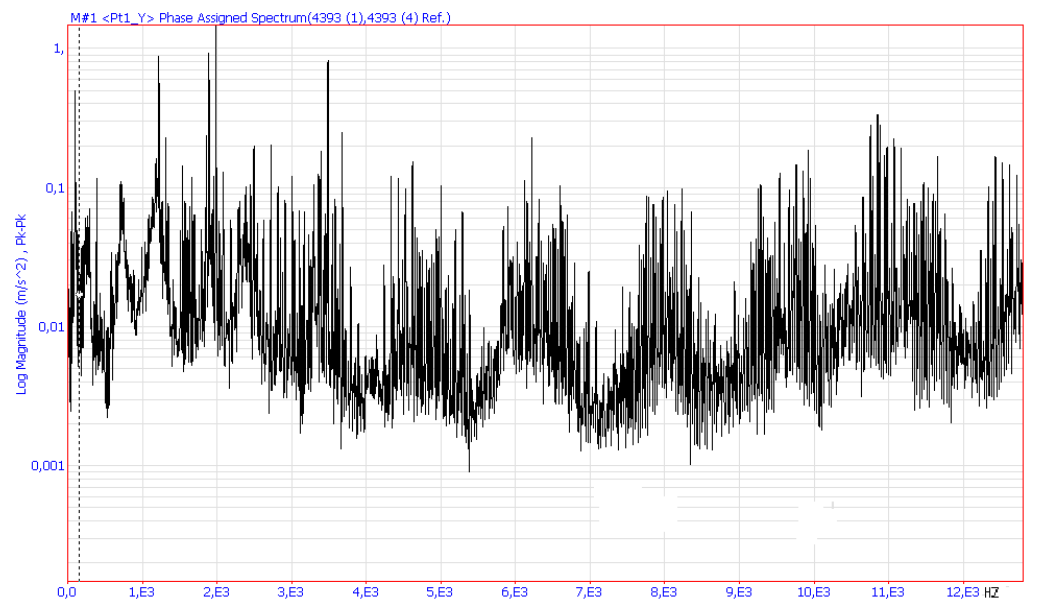

Figure 12: ODS synthesised frequency response function (sinusoidal case, $f_{s}=30 \mathrm{~Hz}$ ) in $[0 \mathrm{~Hz}$, $12800 \mathrm{~Hz}]$ range.

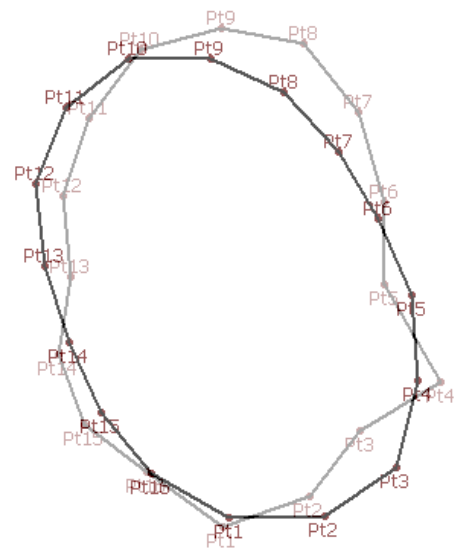

Line nb. 1, c.c. r.

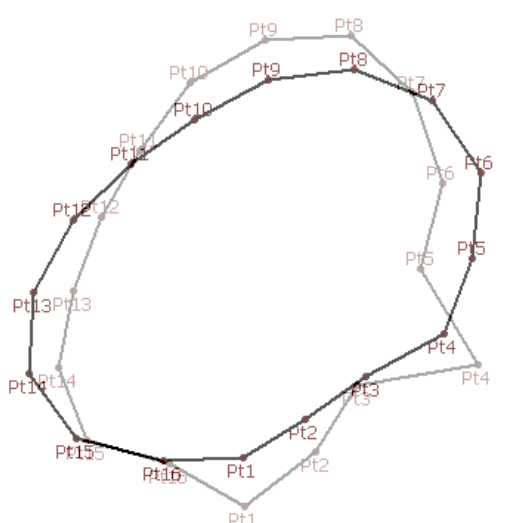

Line nb. 6, c. r.

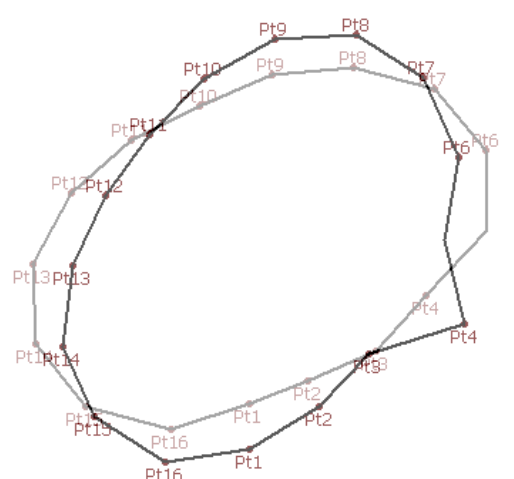

Line nb. 8, c.c. r.

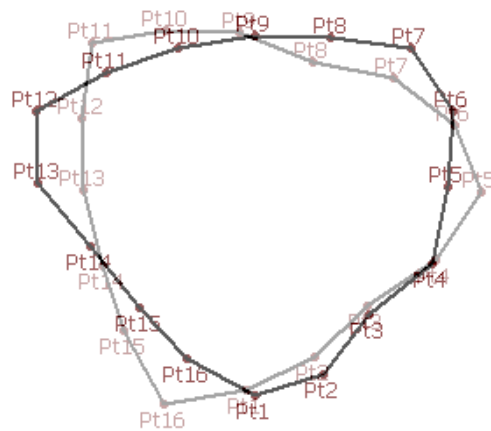

Line nb. 4, c.c. r.

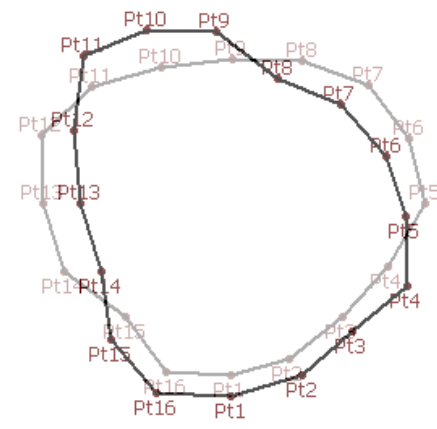

Line nb. 10, c. r.

Figure 13: Operational deflection shapes of the stator under slotting force waves, and their propagation direction (c.c. r.: counter-clockwise rotation, c. r.: clockwise rotation). 

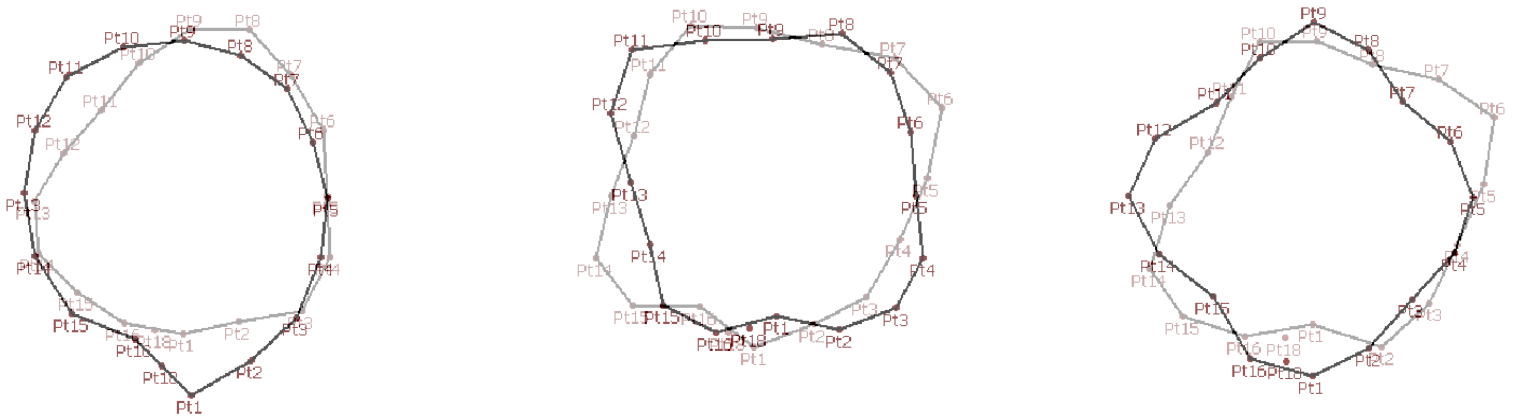

$f=f_{c}-3 f_{s}, m=0$

$f=f_{c}-2 f_{s}, m=-2 p$, c.c. $\mathrm{r}$.

$f=f_{c}-f_{s}, m=2 p$, c. r.
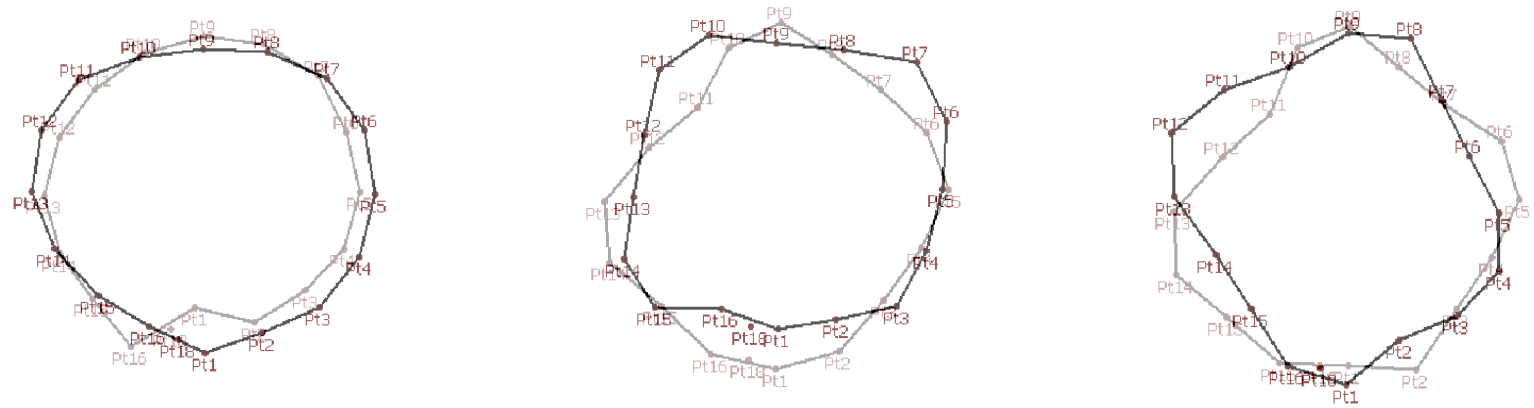

$f=f_{c}, m=0$

$f=f_{c}+f_{s}, m=-2 p$, c.c. $r$.

$f=f_{c}+2 f_{s}, m=2 p$, c. r.

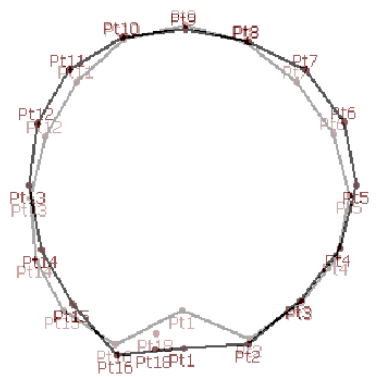

$$
f=f_{c}+3 f_{s}, m=0
$$

Figure 14: Operational deflection shapes of the stator under pure PWM force waves, and their propagation direction (c.c. r.: counter-clockwise rotation, c. r.: clockwise rotation). 